\title{
Structures, Lipophilicity, Dipole Moments, Acidity and Spectroscopic Properties of Non-Steroidal Anti-Inflammatory Drugs Diclofenac, Bromfenac and Amfenac: A Theoretical Study
}

\author{
Assoma Amon Benjamine*, Bede Affoué Lucie, Yapo Kicho Denis, Bamba El Hadji Sawaliho \\ Laboratoire de Chimie Organique et de Substances Naturelles, Université Félix Houphouët-Boigny, Abidjan, Côte d'Ivoire \\ Email: *benassoma@yahoo.fr
}

How to cite this paper: Benjamine, A.A., Lucie, B.A., Denis, Y.K. and El Hadji Sawaliho, B. (2019) Structures, Lipophilicity, Dipole Moments, Acidity and Spectroscopic Properties of Non-Steroidal Anti-Inflammatory Drugs Diclofenac, Bromfenac and Amfenac: A Theoretical Study. Computational Chemistry, 7, 95-105.

https://doi.org/10.4236/cc.2019.74007

Received: August 24, 2019

Accepted: September 27, 2019

Published: September 30, 2019

Copyright $\odot 2019$ by author(s) and Scientific Research Publishing Inc. This work is licensed under the Creative Commons Attribution International License (CC BY 4.0).

http://creativecommons.org/licenses/by/4.0/

\begin{abstract}
This work is a contribution of theoretical chemistry to the classification of some non-steroidal anti-inflammatory drugs (NSAIDs). Indeed, research on the efficacy of NSAIDs has shown that no NSAID is recognized as the most efficient anti-inflammatory drug. We have made a theoretical study of diclofenac, bromfenac and amfenac, in order to compare their efficacy from some physicochemical properties. To do this, we used the DFT and TD-DTF methods at the B3LYP/6-311+G(d,p) level theory. The lipophilicity study shows that diclofenac and bromfenac are very lipophilic. Acidity study shows that diclofenac is more acid than bromfenac and amfenac. The results from molecular orbital and the TD-DFT calculations reveal that for the three NSAIDs, the lowest energy transition is due to the excitation from HOMO to LUMO. The absorption energy corresponding to $\mathrm{H} \rightarrow \mathrm{L}$ transition is comparable with the energy gap value. Our findings have shown that bromfenac is more reactive than amfenac, which is more reactive than diclofenac.
\end{abstract}

\section{Keywords}

Diclofenac, Bromfenac, Amfenac, DFT, Spectroscopic Properties

\section{Introduction}

Non-steroidal anti-inflammatory drugs (NSAIDs) are a set of molecules that have anti-inflammatory, antipyretic and analgesic properties [1] [2]. They are often indicated for treating postoperative pain for surgeries with a predominant 
inflammatory component such as dental surgery, stomatological surgery, maxillofacial surgery, orthopedic surgery and ocular surgery [3] [4] [5] [6]. Indeed, postoperative inflammation is a common condition that can lead to significant complications and to avoid these complications, ophthalmologists commonly use non-steroidal anti-inflammatory drugs. Particularly, in the processes of angiogenic retinal diseases including age-related macular degeneration (AMD) [7], inflammation plays a substantial role. In the field of the treatment of these diseases, NSAIDs are associated with anti-vascular endothelial growth factor (VEGF). That combination of NSAIDs with anti-VEGF significantly reduces the treatment burden of anti-VEGF agents.

Bromfenac, diclofenac and amfenac are the commonly used NSAIDs. Bromfenac is 2-amino-3-(4-bromobenzoyl) phenylacetic acid. It is an NSAID that is widely used as an ophthalmic solution for the treatment of ocular inflammation and pain after cataract surgery and inflammatory diseases of external eye segments [8] [9]. Recent studies have shown that bromfenac inhibits laser-induced choroidal neovascularization in rats [10]. Gomi et al. have reported in humans that the use of topical bromfenac may reduce the frequency of intravitreal injections of Ranibizumab [11]. Although bromfenac has good intraocular penetration in humans [12], the relationship between its efficacy and pharmacokinetics has not been determined [13]. This led Tetsuo et al to determine the drug levels of bromfenac, diclofenac, and amfenac in the retinochoroidal tissues of rabbits by liquid chromatography-tandem mass spectrometry (LC-MS/MS) [14]. Their studies' findings showed that bromfenac has a stronger inhibitory activity on COX-1 or COX-2 than amfenac or diclofenac. However, there is no theoretical data that can confirm these results.

Verification of these experimental results remains at the center of our team's concerns. The present research aims to investigate the structure, lipophilicity, dipole moment, stability, acidity, and spectroscopic properties of diclofenac, bromfenac and amfenac. This would allow to know their mode of action and to design derivatives with more efficacies. To do this, we use DFT [15] [16] and TD-DFT [17] [18] methods with the B3LYP functional.

\section{Methods of Calculation}

Calculations on the ground state geometries are carried out with DFT (B3LYP functional) using 6-311+G(d,p) basis set [15] [16]. The absorption spectrum are calculated using TD-DFT method at B3LYP/6-311+G(d,p) level of theory [17] [18]. The ground state optimization and spectral calculations are carried out in gas and aqueous phases and using Tomasi's conductor-like polarizable continuum model (CPCM) [19]. The Gibbs free energies are obtained from the calculation of the frequencies. Frequency analyses were proceeded to confirm the structure being a minimum or a transition state (i.e. without or with solely an imaginary frequency). These calculations are carried out with the GAUSSIAN-09 program [20]. The freeware ACD/ChemSketch is used for LogP calculation. 


\section{Results and Discussions}

Generally, the absorption of drugs through the cornea is dependent upon their physicochemical properties. The results concern the lipophilicity, the dipole moment, the acidity, and the spectroscopic properties of diclofenac, bromfenac and amfenac. Previously, they focus on their structures. These results will allow making a comparison of their efficacy.

\subsection{Structures}

The important structural parameters of diclofenac, bromfenac and amfenac are those of the carboxylic group (Figure 1). The calculated values are in Table 1.

In the gas phase, the length of the $\mathrm{O}-\mathrm{H}$ bond is $0.970 \AA$ in all the molecules. The single $\mathrm{C}$-O bond is $1.355 \AA$ in bromfenac. It is $0.001 \AA$ longer in amfenac and $0.003 \AA$ longer in diclofenac. The length of the $\mathrm{C}=\mathrm{O}$ double bond is $1.204 \AA$ in the three molecules. The bond angle $\mathrm{HO}-\mathrm{C}=\mathrm{O}$, is $122.6^{\circ}$ in bromfenac and amfenac; it is $0.2^{\circ}$ shorter in diclofenac. In the aqueous phase, the $\mathrm{O}-\mathrm{H}$ and $\mathrm{C}=\mathrm{O}$ bonds remain identical for the three molecules. The $\mathrm{O}-\mathrm{H}$ bond is $0.971 \AA$ and the $\mathrm{C}=\mathrm{O}$ bond is $1.210 \AA$. They increase by $0.001 \AA$ and $0.006 \AA$ respectively compared to the gas phase. The $\mathrm{C}-\mathrm{O}$ single bond is $1.347 \AA$ in bromfenac and amfenac and $1.348 \AA$ in diclofenac. This bond is thus shortened in the aqueous phase. The bond angle $\mathrm{HO}-\mathrm{C}=\mathrm{O}$, increases in the aqueous phase; it is $122.7^{\circ}$ in bromfenac and amfenac and $122.6^{\circ}$ in diclofenac. The chemical structures of bromfenac and amfenac are structurally identical with the exception of a bromine atom at the $\mathrm{C} 4$ position (Figure 1); the structural parameters are not affected by the substitution.

\subsection{Lipophilicity and Dipole Moments}

Lipophilicity is important in the design of a drug. It allows knowing if the molecule is more likely to be hydrophilic, or more likely to be lipophilic. It has often been used as a criterion for comparing several drugs [21] [22] [23]. We have used the freeware ACD/ChemSketch to calculate the LogP. Calculated lipophilicity $(\log \mathrm{P})$ parameters and dipole moments are shown in Table 2.

The $\log \mathrm{P}$ value of diclofenac is 4.06 , that of bromfenacis 2.73 and that of amfenac is 1.78 . The three NSAIDs are lipophilic; however diclofenac and bromfenac are very lipophilic. The values of the dipole moment in the gas phase show<smiles>O=C(O)Cc1ccccc1Nc1c(Cl)cccc1Cl</smiles><smiles>Nc1c(CC(=O)O)cccc1C(=O)c1ccc(Br)cc1</smiles>

Bromfenac<smiles>Nc1c(CC(=O)O)cccc1C(=O)c1ccccc1</smiles>

Amfenac

Figure 1. Chemical structures of diclofenac, bromfenac and amfenac. 
Table 1. Geometrical parameters (bond length in $\AA$, angle in degrees) in gas and aqueous phases.

\begin{tabular}{ccccccc}
\hline \multirow{2}{*}{ Parameters } & \multicolumn{3}{c}{ Gas phase } & \multicolumn{3}{c}{ Aqueous phase } \\
\cline { 2 - 7 } & Diclofenac & Bromfenac & Amfenac & Diclofenac & Bromfenac & Amfenac \\
\hline O-H & 0.970 & 0.970 & 0.970 & 0.971 & 0.971 & 0.971 \\
C-O & 1.358 & 1.355 & 1.356 & 1.348 & 1.347 & 1.347 \\
C=O & 1.204 & 1.204 & 1.204 & 1.210 & 1.210 & 1.210 \\
HO-C=O & 122.4 & 122.6 & 122.6 & 122.6 & 122.7 & 122.7 \\
\hline
\end{tabular}

Table 2. Calculated and experimental lipophilicity $(\log \mathrm{P})$ parameters and dipole moments $(\mu)$.

\begin{tabular}{ccccc}
\hline Compounds & $\log \mathrm{P}$ & $\log \mathrm{P}_{\text {Exp }}$ & $\mu_{\text {gas }}(\mathrm{D})$ & $\mu_{\text {aqueous }}(\mathrm{D})$ \\
\hline Diclofenac & $4.06 \pm 0.41$ & $4.51^{\mathrm{a}}$ & 2.65 & 3.97 \\
Bromfenac & $2.073 \pm 0.61$ & $3.4^{\mathrm{b}}$ & 2.25 & 3.35 \\
Amfenac & $1.78 \pm 0.59$ & & 1.39 & 2.25
\end{tabular}

${ }^{\mathrm{a}}$ https://www.drugbank.ca/drugs/DB00586; ${ }^{\mathrm{b}}$ https://www.drugbank.ca/drugs/DB00963.

that diclofenac, possess the highest value of dipole moment $(2.65 \mathrm{D})$ and bromfenac with a dipole moment of $2.25 \mathrm{D}$ is more polar than amfenac $(1.39 \mathrm{D})$. Thus the substitution of bromine at the $\mathrm{C} 4$ position of amfenac increases the dipole moment. These values increase clearly in aqueous phase. This result is in good agreement with that of the lipophilicity. The preceding results make it possible to discuss the acidity of NSAIDs because lipophilicity, polarity and acidity are related.

\subsection{Acidity}

It is known that most of the anti-inflammatory drugs are carboxylic acids in which the carboxylic group is available for metal-ligand interactions [24] [25]. Indeed, the carboxylic acid group is ionizable at physiological $\mathrm{pH}$. The anionic charge allows anchoring of the NSAID in the catalytic site by establishing an electrostatic interaction with a positively charged cox enzyme residue. It is important to know their acidic characteristics. The gas phase energy $\Delta G$ of the proton abstraction can helps to evaluate the acidity [26]. It may be calculated from the following equations:

$$
\begin{gathered}
\mathrm{AH} \rightarrow \mathrm{A}^{-}+\mathrm{H}^{+} . \\
\Delta G=G\left(\mathrm{~A}^{-}\right)+G\left(\mathrm{H}^{+}\right)-G(\mathrm{AH})
\end{gathered}
$$

In gas phase, $\mathrm{G}_{\mathrm{g}}\left(\mathrm{H}^{+}\right)=2.5 \mathrm{RT}-\mathrm{T} \Delta \mathrm{S}=1.48-7.76=-6.28 \mathrm{kcal} / \mathrm{mol}$ [27] [28] . This method has been used to determine the acidity of several molecules [29] [30] [31] [32]. Table 3 presents the results of the calculations. The weaker $\Delta \mathrm{G}$ is, the more the oxygen atom is acidic. Under these conditions, in the gas phase, diclofenac is more acid than bromfenac and amfenac. This result agrees with lipophilicity and dipole moments. 
Table 3. Gas phase acidity: $\Delta \mathrm{G}(\mathrm{kJ} / \mathrm{mol})$.

\begin{tabular}{ccc}
\hline Compounds & $\mathrm{G}_{\mathrm{g}}(\mathrm{au})$ & $\Delta \mathrm{G}_{\mathrm{g}}(\mathrm{KJ} / \mathrm{mol})$ \\
\hline Diclofenac & -1665.80756 & \\
Diclofenac (O-anion) & -1665.144766 & 1712.2 \\
Bromfenac & -3433.469536 & \\
Bromfenac (O-anion) & -3432.805887 & 1714.5 \\
Amfenac & -859.913231 & \\
Amfenac (O-anion) & -859.250338 & 1712.5 \\
\hline
\end{tabular}

\subsection{Spectroscopic Properties}

In this part, we analyzed the frontier molecular orbitals and absorption properties.

\subsubsection{Frontier Molecular Orbitals (FMOs)}

Frontier molecular orbitals (FMOs) known as highest occupied molecular orbital (HOMO) and lowest unoccupied molecular orbital (LUMO) respectively, plays a vital role in chemical reactions of any molecule, as well as absorption spectra [33] [34]. According to Koopman's theorem [35] associated within the framework of HF self-consistent field molecular orbital theory, the ionization energy (I) and electron affinity (A) can be stated through HOMO and LUMO orbital energies as:

$$
\begin{aligned}
& I=-E_{\text {номо }} \\
& A=-E_{\text {LUМО }}
\end{aligned}
$$

Higher HOMO energy is corresponds to the more reactive molecule in the reactions with electrophiles, while lower LUMO energy is essential for molecular reactions with nucleophiles [36]. Therefore, hardness of any materials is corresponds to the gap between the HOMO and LUMO orbitals. It clearly indicates that if the HOMO-LUMO energy gap is larger than molecule will be harder [37] [38]. The Hardness $(\eta)$ of a molecule is calculated by:

$$
\eta=\frac{1}{2}\left(E_{\text {LUмо }}-E_{\text {номо }}\right)=\frac{1}{2}(\Delta E)=\frac{1}{2}(I-A)
$$

The calculated values of $\Delta E$ and $\eta$ are presented in Table 4 . In gas phase, the energy gap of bromfenac is $3.93 \mathrm{eV}$ followed by amfenac at $4.00 \mathrm{eV}$ and diclofenac at $4.91 \mathrm{eV}$. Bromfenac is therefore more reactive than amfenac followed by diclofenac. Indeed more $\Delta E$ is small more the molecule is reactive. The energy gap values decrease in aqueous phase for the three molecules. These molecules are more reactive in aqueous solution. Furthermore, bromfenac has a chemical hardness value of $1.96 \mathrm{eV}$ followed by amfenac with a value of $2.00 \mathrm{eV}$ and diclofenac with a value of $2.45 \mathrm{eV}$. These values suggest that bromfenac is less hard than amfenac followed by diclofenac. The same observations are made in aqueous phase. In general, halogenation enhances the potency of medicinal compounds $\left(\mathrm{Br}^{-} \sim \mathrm{I}^{-}>\mathrm{Cl}^{-}>\mathrm{F}^{-}>\mathrm{H}\right)$ [39]. This confirms our results. 
Table 4. Molecular orbital energies $\left(E_{\text {НОМO }} E_{L U M O}\right)$, energy gap $\Delta E$ and hardness $\eta(\mathrm{eV})$.

\begin{tabular}{lcccccccc}
\hline \multirow{3}{*}{ Compounds s } & \multicolumn{3}{c}{ Gas phase } & & & \multicolumn{3}{c}{ Aqueous phase } \\
\cline { 2 - 8 } & $E_{\text {HOMO }}$ & $E_{L U M O}$ & $\Delta E$ & $\eta$ & $E_{\text {HOMO }}$ & $E_{L U M O}$ & $\Delta E$ & $\eta$ \\
\hline Diclofenac & -6.092 & -1.187 & 4.91 & 2.45 & -6.109 & -1.128 & 4.980 & 2.49 \\
Bromfenac & -6.149 & -2.215 & 3.93 & 1.96 & -6.112 & -2.232 & 3.880 & 1.94 \\
Amfenac & -6.038 & -2.038 & 4.00 & 2.00 & -6.091 & -2.152 & 3.940 & 1.97 \\
\hline
\end{tabular}

\subsubsection{Absorption Properties}

The spectral studies of diclofenac, bromfenac and amfenac have been performed using TD-DFT at B3LYP/6-311+G(d,p) level of theory in gas and aqueous phases. TD-DFT is a reliable method for the excited state computation [40] [41] that provide accurate results. To obtain the nature and energy of the singlet-singlet electronic transition, the prediction of the first 3 excited states are performed. The calculated absorption energy, corresponding oscillator strength and orbital coefficients are summarized in Table 5. The results show that for all the molecules, the lowest energy transition is due to the excitation of electron from HOMO to the LUMO. The absorption maxima $\left(\lambda_{\max }\right)$ of the three molecules, diclofenac, bromfenac and amfenac correspond to the $\mathrm{H} \rightarrow \mathrm{L}$ transition. In gas phase, the absorption maxima $\left(\lambda_{\max }\right)$ of bromfenac is $7 \mathrm{~nm}$ greater than that of amfenac. This means that replacing a hydrogen atom with a bromine atom is accompanied by a bathochromic effect that decreases the absorption energy. Thus for the absorption maxima, the energy of bromfenac $(3.36 \mathrm{eV})$ is smaller than that of amfenac $(3.42 \mathrm{eV})$ which is smaller than that of diclofenac $(4.20 \mathrm{eV})$.

The absorption intensity is directly related with the dimensionless oscillator strength and the dominant absorption bands are the transitions with higher oscillator strength value [36]. Figure 2 shows the variation of the absorption energies in gas and aqueous phases as a function of the oscillator strength. In gas phase, the absorption spectrum of diclofenac has one peak observed at $4.36 \mathrm{eV}$ $(284 \mathrm{~nm})$, it is associated with the $\mathrm{H}(\mathrm{HOMO}) \rightarrow \mathrm{L}+1(\mathrm{LUMO}+1)$ transition. The absorption spectrum of bromfenac has two peaks, the maximum peak is observed at $4.39 \mathrm{eV}(282 \mathrm{~nm})$ associated with $\mathrm{H}-1 \rightarrow \mathrm{L}$ transition and second peak at $3.36 \mathrm{eV}(369 \mathrm{~nm})$ corresponding to $\mathrm{H} \rightarrow \mathrm{L}$ transition. For amfenac, the absorption spectrum has one peak observed at $3.42 \mathrm{eV}(362 \mathrm{~nm})$, is associated with the $\mathrm{H} \rightarrow \mathrm{L}$ transition. It has been observed that for all the studied molecules, the absorption wavelength calculated in gas phase and in aqueous phases is nearly similar and the maximum variation is only around $9 \mathrm{~nm}$. Thus the solvent influences little the absorption spectrum. For diclofenac and bromfenac, we observe the same number of peaks with the same transitions. For amfenac we can observe a second peak at $4.479 \mathrm{eV}(277 \mathrm{~nm})$ which is associated with the $\mathrm{H}-2 \rightarrow \mathrm{L}$ transition. In general, the absorption energies of bromfenac are lower than those of amfenac, which are themselves lower than those of diclofenac. It is interesting to note that the absorption energy corresponding to $\mathrm{H} \rightarrow \mathrm{L}$ transition is comparable with the energy gap value. The molecule with a small $\mathrm{H} \rightarrow \mathrm{L}$ energy gap possess 
Table 5. Absorption energy ( $\mathrm{nm}$ and $\mathrm{eV}$ ) and oscillator strengths $\mathrm{f}$ (a.u.) of diclofenac, bromfenac and amfenac calculated at TD-B3LYP/6-311+G(d,p) level of theory in gas and aqueous phases.

\begin{tabular}{ccccccccc}
\hline \multirow{2}{*}{ Compounds } & \multicolumn{3}{c}{ Gas phase } & \multicolumn{4}{c}{ Aqueous phase } \\
\cline { 2 - 9 } & $\begin{array}{c}\text { Orbital } \\
\text { transitions }\end{array}$ & $\begin{array}{c}\text { Absorption } \\
\text { energy }\end{array}$ & $\begin{array}{c}\text { Oscillator } \\
\text { strength }\end{array}$ & $\begin{array}{c}\text { Orbital } \\
\text { transitions }\end{array}$ & $\begin{array}{c}\text { Absorption } \\
\text { energy }\end{array}$ & $\begin{array}{c}\text { Oscillator } \\
\text { strength }\end{array}$ \\
\hline & & $\mathrm{nm}$ & $\mathrm{eV}$ & $\mathrm{f}$ (a.u.) & & $\mathrm{nm}$ & $\mathrm{eV}$ & $\mathrm{fa}$ a.u. \\
\hline \multirow{3}{*}{ Diclofenac } & $\mathrm{H} \rightarrow \mathrm{L}(0.678)$ & 295 & 4.200 & 0.015 & $\mathrm{H} \rightarrow \mathrm{L}(0.659)$ & 291 & 4.257 & 0.019 \\
& $\mathrm{H} \rightarrow \mathrm{L}+1(0.690)$ & 284 & 4.363 & 0.282 & $\mathrm{H} \rightarrow \mathrm{L}+1(0.672)$ & 286 & 4.339 & 0.331 \\
& $\mathrm{H} \rightarrow \mathrm{L}+2(0.639)$ & 262 & 4.739 & 0.007 & $\mathrm{H} \rightarrow \mathrm{L}+2(0.617)$ & 265 & 4.687 & 0.024 \\
\hline \multirow{3}{*}{ Bromfenac } & $\mathrm{H} \rightarrow \mathrm{L}(0.695)$ & 369 & 3.362 & 0.153 & $\mathrm{H} \rightarrow \mathrm{L}(0.698)$ & 377 & 3.291 & 0.194 \\
& $\mathrm{H}-3 \rightarrow \mathrm{L}(0.438)$ & 328 & 3.775 & 0.002 & $\mathrm{H}-1 \rightarrow \mathrm{L}(0.440)$ & 323 & 3.834 & 0.007 \\
& $\mathrm{H}-1 \rightarrow \mathrm{L}(0.513)$ & 282 & 4.394 & 0.261 & $\mathrm{H}-1 \rightarrow \mathrm{L}(0.499)$ & 283 & 4.374 & 0.291 \\
\hline \multirow{3}{*}{ Amfenac } & $\mathrm{H} \rightarrow \mathrm{L}(0.691)$ & 362 & 3.423 & 0.133 & $\mathrm{H} \rightarrow \mathrm{L}(0.697)$ & 371 & 3.343 & 0.175 \\
& $\mathrm{H}-1 \rightarrow \mathrm{L}(0.590)$ & 328 & 3.781 & 0.001 & $\mathrm{H}-1 \rightarrow \mathrm{L}(0.567)$ & 323 & 3.840 & 0.001 \\
& $\mathrm{H} \rightarrow \mathrm{L}+1(0.557)$ & 274 & 4.520 & 0.006 & $\mathrm{H}-2 \rightarrow \mathrm{L}(0.579)$ & 277 & 4.479 & 0.035 \\
\hline
\end{tabular}

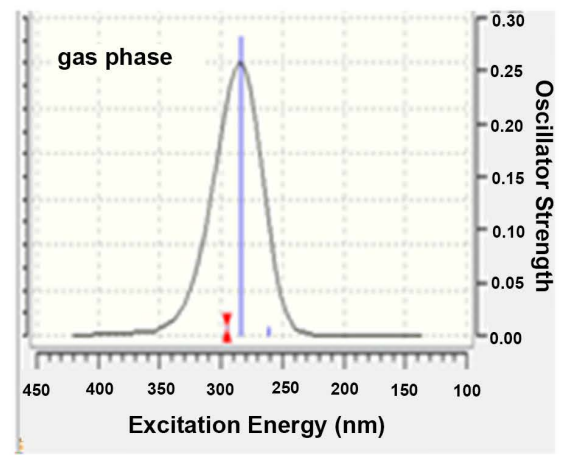

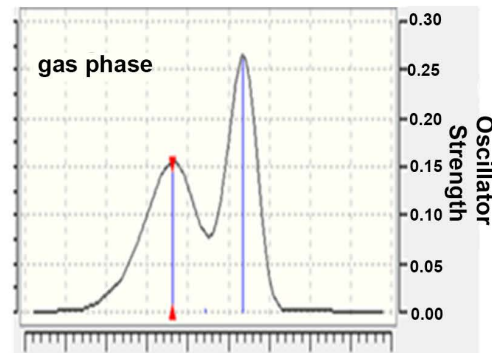

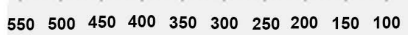

Excitation Energy (nm)

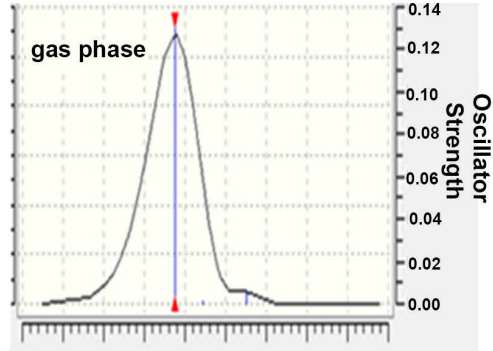

$550500450400350300250200 \quad 150100$

Excitation Energy (nm)

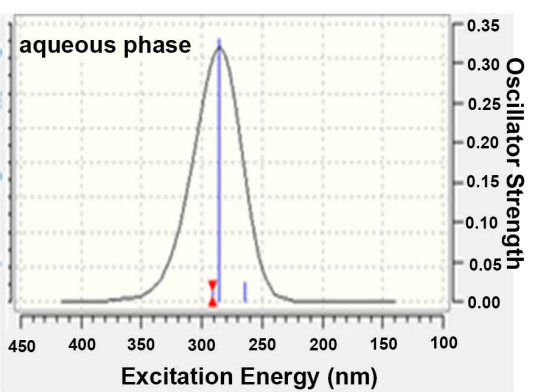

diclofenac

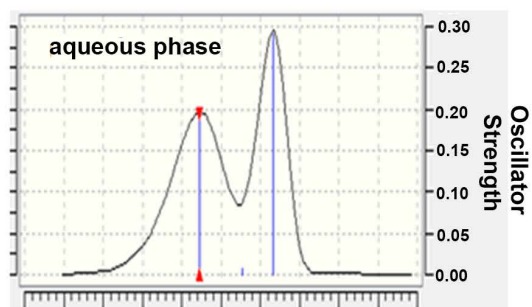

$600550500450400350300250200 \quad 150100$

Excitation Energy $(\mathrm{nm})$

bromfenac

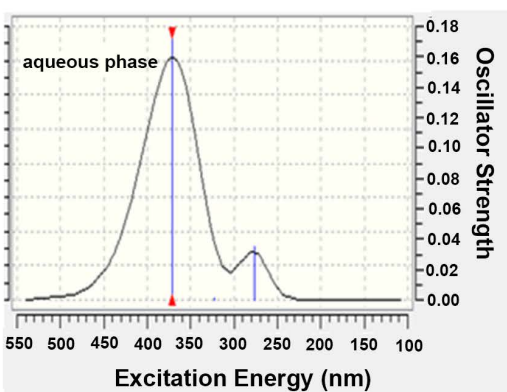

amfenac

Figure 2. Absorption spectra of diclofenac, bromfenac and amfenac.

maximum absorption wavelength. This means that bromfenac is effectively more reactive than amfenac followed by diclofenac. This result is in agreement with experimental studies of Led Tetsuo et al. that have shown that bromfenac had a stronger inhibitory activity on COX-1 or COX-2 than amfenac or diclofenac [14]. It is also compatible with earlier reports [42] [43] [44] [45]. 


\section{Conclusion}

We have studied some physicochemical properties of diclofenac, bromfenac and amfenac using the DFT and TD-DFT methods. The study of the structures of diclofenac, bromfenac and amfenac reveals a slight variation in the values of the geometrical parameters of the carboxylic group. The lipophilicity study shows that, diclofenac and bromfenac are very lipophilic. The evaluation of the polarity through the dipole moment shows that diclofenac is more polar than bromfenac followed by amfenac. The dipole moments increase with the polarity of the medium. In terms of acidity, research establishes that in the gas phase, diclofenac is more acid than bromfenac and amfenac. The energy gap indicates that bromfenac is more reactive than amfenac followed by diclofenac. This result is confirmed by that of TD-DFT calculations. Indeed TD-DFT calculations show that for the three NSAIDs, the lowest energy transition is due to the excitation from HOMO to LUMO. The absorption energy corresponding to $\mathrm{H} \rightarrow \mathrm{L}$ transition is comparable with the energy gap value. Moreover, this work opens new perspectives; in particular, its results could help to establish a classification of efficacy of NSAIDs.

\section{Acknowledgements}

I would like to thank Professor BAMBA El Hadji Sawaliho for his advice.

\section{Conflicts of Interest}

The authors declare no conflicts of interest regarding the publication of this paper.

\section{References}

[1] Jubert, A., Legarto, M.L., Massa, N.E., Tevez, L.L. and Okulik, N.B. (2006) Vibrational and Theoretical Studies of Non-Steroidal Anti-Inflammatory Drugs Ibuprofen [2-(4-isobutylphenyl)propionic acid]; Naproxen [6-methoxy-a-methyl-2-naphthalene acetic acid] and Tolmetin Acids [1-methyl-5-(4-methylbenzoyl) 1H-pyrrole-2-acetic acid]. Journal of Molecular Structure, 783, 34-51.

[2] Darinee, S.-T., Prasat, K. and Supa, H.A. (2009) Roles of Key Residues Specific to Cyclooxygenase II: An ONIOM Study. Monatshefte für Chemie, 140, 1533-1541. https://doi.org/10.1007/s00706-009-0194-7

[3] Waterbury, L., Kunysz, E.A. and Beuerman, R. (1987) Effects of Steroidal and Nonsteroidal Anti-Inflammatory Agents on Corneal Wound Healing. Journal of Ocular Pharmacology and Therapeutics, 3, 43-54. https://doi.org/10.1089/jop.1987.3.43

[4] Schalnus, R. (2003) Topical Nonsteroidal Anti-Inflammatory Therapy in Ophthalmology. Ophthalmologica, 217, 89-98. https://doi.org/10.1159/000068563

[5] Donnenfeld, E.D., Holland, E.J., Stewart, R.H., Gow, J.A., Grillone, L.R., Bromfenac Ophthalmic Solution 0.09\% (Xibrom) Study Group (2007) Bromfenac Ophthalmic Solution $0.09 \%$ (Xibrom) for Postoperative Ocular Pain and Inflammation. Ophthalmology, 114, 1653-1662. https://doi.org/10.1016/j.ophtha.2006.12.029

[6] Uchio, E., Itoh, Y. and Kadonosono, K. (2007) Topical Bromfenac Sodium for LongTerm Management of Vernal Keratoconjunctivitis. Ophthalmologica, 221, 153-158. 
https://doi.org/10.1159/000099294

[7] Telander, D.G. (2011) Inflammation and Age-Related Macular Degeneration (AMD). Seminars in Ophthalmology, 26, 192-197. https://doi.org/10.3109/08820538.2011.570849

[8] Jones, J. and Francis, P. (2009) Ophthalmic Utility of Topical Bromfenac, a Twice-Daily Nonsteroidal Anti-Inflammatory Agent. Expert Opinion on Pharmacotherapy, 10, 2379-2385. https://doi.org/10.1517/14656560903188425

[9] Cho, H., Wolf, K.J. and Wolf, E.J. (2009) Management of Ocular Inflammation and Pain Following Cataract Surgery: Focus on Bromfenac Ophthalmic Solution. Clinical Ophthalmology, 3, 199-210. https://doi.org/10.2147/OPTH.S4806

[10] Yoshinaga, N., Arimura, N., Otsuka, H., Kawahara, K. and Hashiguchi, T. (2011) NSAIDs Inhibit Neovascularization of Choroid through HO-1-Dependent Pathway. Laboratory Investigation, 91, 1277 1290. https://doi.org/10.1038/labinvest.2011.101

[11] Gomi, F., Sawa, M., Tsujikawa, M. and Nishida, K. (2012) Topical Bromfenac as an Adjunctive Treatment with Intravitreal Ranibizumab for Exudative Age-Related Macular Degeneration. Retina, 32, 1804-1810. https://doi.org/10.1097/IAE.0b013e31825be87f

[12] Miyake, K., Ogawa, T., Tajika, T., Gow, J.A. and McNamara, T.R. (2008) Ocular Pharmacokinetics of a Single Dose of Bromfenac Sodium Ophthalmic Solution 0.1\% in Human Aqueous Humor. Journal of Ocular Pharmacology and Therapeutics, 24, 573-578. https://doi.org/10.1089/jop.2007.0132

[13] Baklayan, G.A., Patterson, H.M., Song, C.K., Gow, J.A. and McNamara, T.R. (2008) 24-Hour Evaluation of the Ocular Distribution of (14)C-Labeled Bromfenac Following Topical Instillation into the Eyes of New Zealand White Rabbits. Journal of Ocular Pharmacology and Therapeutics, 24, 392-398. https://doi.org/10.1089/jop.2007.0082

[14] Kida, T., Kozai, S., Takahashi, H., Isaka, M. and Tokushige, H. (2014) Pharmacokinetics and Efficacy of Topically Applied Nonsteroidal Anti-Inflammatory Drugs in Retinochoroidal Tissues in Rabbits. PLoS ONE, 9, e96481.

[15] Becke, A.D. (1998) Density-Functional Exchange-Energy Approximation with Correct Asymptotic Behavior. Physical Review A, 38, 3098-3100. https://doi.org/10.1103/PhysRevA.38.3098

[16] Lee, C., Yang, W. and Parr, R.G. (1988) Development of the Colle-Salvetti Correlation-Energy Formula into a Functional of the Electron Density. Physical Review B, 37, 785-789. https://doi.org/10.1103/PhysRevB.37.785

[17] Casida, M.E. (1995) Recent Advances in Density Functional Methods, Part I. World Scientific, Singapore.

[18] Gross, E.K.U., Dobson, J.F. and Petersilka, M. (1996) Density Functional Theory II. Springer, Heidelberg, 181.

[19] Miertus, S., Scrocco, E. and Tomasi, J. (1981) Electrostatic Interaction of a Solute with a Continuum. A Direct Utilization of $a b$ Initio Molecular Potentials for the Prevision of Solvent Effects. The Journal of Chemical Physics, 55, 117-129. https://doi.org/10.1016/0301-0104(81)85090-2

[20] Frisch, M.J., Trucks, G.W., Schlegel, H.B., Scuseria, G.E., Robb, M.A., Cheeseman, J.R., et al. (2009) Gaussian09, Revision A.02. Gaussian, Inc., Wallingford.

[21] Remko, M., Remková, A. and Broer, R. (2016) Theoretical Study of Molecular Structure and Physicochemical Properties of Novel Factor Xa Inhibitors and Dual Factor Xa and Factor IIa Inhibitors. Molecules, 21, 185. 
https://doi.org/10.3390/molecules21020185

[22] Remko, M., Broer, R. and Remková, A. (2014) A Comparative Study of the Molecular Structure, Lipophilicity, Solubility, Acidity, Absorption and Polar Surface Area of Coumarinic Anticoagulants and Direct Thrombin Inhibitors. RSC Advances, 4, 8072-8084. https://doi.org/10.1039/C3RA42347F

[23] Remko, M., Remková, A. and Broer, R. (2016) A Comparative Study of Molecular Structure, pKa, Lipophilicity, Solubility, Absorption and Polar Surface Area of Some Antiplatelet Drugs. International Journal of Molecular Sciences, 17, 388. https://doi.org/10.3390/ijms17030388

[24] Sorenson, J.R. (1976) Copper Chelates as Possible Active Forms of the Antiarthritic Agents. Journal of Medicinal Chemistry, 19, 135-148. https://doi.org/10.1021/jm00223a024

[25] Sorensen, J.R. (1982) Metal Ions in Biological Systems. Marcel Dekker, New York, Vol. 14, 77-124.

[26] Milan, R. (2003) Theoretical Study of Molecular Structure and Gas-Phase Acidity of Some Biologically Active Sulfonamides. The Journal of Physical Chemistry A, 107, 720-725. https://doi.org/10.1021/jp026980m

[27] Lim, C., Bashford, D. and Karplus, M. (1991) Absolute pKa Calculations with Continuum Dielectric Methods. The Journal of Physical Chemistry, 95, 5610-5620. https://doi.org/10.1021/j100167a045

[28] Topol, I.A., Tawa, G.J., Burt, S.K. and Rashin, A.A. (1997) Calculation of Absolute and Relative Acidities of Substituted Imidazoles in Aqueous Solvent. The Journal of Physical Chemistry A, 101, 10075-10081. https://doi.org/10.1021/jp9723168

[29] Assoma, A.B., Bede, A.L., Kone, M. and N'Guessan, Y.T. (2010) Theoretical Study of Stability, Tautomerism, Equilibrium Constants (pkT), Activation Energies and Acidity of 6-Thioxanthine in Gas and Aqueous Phase by the Ab Initio Method and Functional Density Theory Calculations. European Journal of Scientific Research, 44, 337-354.

[30] Assoma, A.B., Bede, A.L., Yapo, K.D., N’Guessan, B.R. and Bamba, E.-H.S. (2018) Étude Théorique de la Stabilité, de la Tautomérie et de L'acidité de la 2,6-Dithioxanthine Par la Méthode de la Théorie de la Fonctionnelle de Densité. European Journal of Scientific Research, 149, 148-152.

[31] Assoma, B.A., Bede, L.A., N’Guessan, R.B., Kone, S., Bamba, S.E. and N'Guessan, T.Y. (2018) Stability, Tautomerism and Acidity of Xanthine by the Density Functional Theory (DFT). Journal of Current Chemical and Pharmaceutical Sciences, 8, 114.

[32] Assoma, A.B., Kone, M., Alao, L.L, Bede, A.L., Kone, S., N'Guessan, B.R., Bamba, E.-H.S. and N'guessan, Y.T. (2019) Density Functional Theory (B3LYP/6-311+G(d, p)) Study of Stability, Tautomerism and Acidity of 2-Thioxanthine in Gas and Aqueous Phases. International Journal of Computational and Theoretical Chemistry, 7, 49-55.

[33] Mohd, S., AlFaify, S., Haider, A. and Shabbir, M. (2015) First Principal Studies of Spectroscopic (IR and Raman, UV-Visible), Molecular Structure, Linear and Nonlinear Optical Properties of L-Arginine p-Nitrobenzoate Monohydrate (LANB): A New Non-Centrosymmetric Material. Spectrochimica Acta Part A: Molecular and Biomolecular Spectroscopy, 147, 84-92. https://doi.org/10.1016/j.saa.2015.02.111

[34] Bede, A.L., Assoma, A.B., Yapo, K.D., Kone, M.G.-R., Kone, S., Kone, M., N'Guessan, B.R. and Bamba, E.-H.S. (2018) Theoretical Study by Density Functional Theory Method (DFT) of Stability, Tautomerism, Reactivity and Prediction of Acidity of Quinolein-4-One Derivatives. Computational Chemistry, 6, 57-70. https://doi.org/10.4236/cc.2018.63005 
[35] Koopmans, T. (1933) Über die Zuordnung von Wellenfunktionen und Eigenwerten zu den Einzelnen Elektronen Eines Atoms. Physica, 1, 104-113. https://doi.org/10.1016/S0031-8914(34)90011-2

[36] Rauk, A. (2001) Orbital Interaction Theory of Organic Chemistry. 2nd Edition, John Wiley \& Sons, New York, 34. https://doi.org/10.1002/0471220418

[37] Pearson, R.G. (1985) Absolute Electronegativity: An Hardness Correlated. Journal of the American Chemical Society, 107, 6801-6806. https://doi.org/10.1021/ja00310a009

[38] Pearson, R.G. (1987) Recent Advances in the Concept of Hard and Soft Acids and Bases. Journal of Chemical Education, 64, 561-567. https://doi.org/10.1021/ed064p561

[39] Walsh, D.A., Moran, H.W., Shamblee, D.A., Uwaydah, I.M., Welstead, W.J.Jr., et al. (1984) Antiinflammatory Agents 3 Synthesis and Pharmacological Evaluation of 2-amino-3-benzoylphenyl Acetic Acid and Analogues. Journal of Medicinal Chemistry, 11, 1379-1388. https://doi.org/10.1021/jm00377a001

[40] Wang, D., Hao, C., Wang, S., Dong, H. and Qiu, J. (2012) Time-Dependent Density Functional Theory Study on the Electronic Excited-State Hydrogen Bonding of the Chromophore Coumarin 153 in a Room Temperature Ionic Liquid. Journal of Molecular Modeling, 18, 937-945. https://doi.org/10.1007/s00894-011-1131-3

[41] Mylsamy, K., Ramasamy, K. and Lakshmipathi, S. (2013) Spectroscopic Investigations and Hydrogen Bond Interactions of 8-Aza Analogues of Xanthine, Theophylline and Caffeine: A Theoretical Study. Journal of Molecular Modeling, 19, 1835-1851. https://doi.org/10.1007/s00894-012-1742-3

[42] Kim, S.J., Flach, A.J. and Jampol, L.M. (2010) Nonsteroidal Anti-Inflammatory Drugs in Ophthalmology. Survey of Ophthalmology, 55, 108-133. https://doi.org/10.1016/j.survophthal.2009.07.005

[43] Ruiz, J., López, M., Mila, J., Lozoya, E. and Lozano, J.J. (1993) QSAR and Conformational Analysis of the Antiinflammatory Agent Amfenac and Analogues. Journal of Computer-Aided Molecular Design, 7, 183-198. https://doi.org/10.1007/BF00126444

[44] Ogawa, T., Sakaue, T., Terai, T. and Fukiage, C. (1995) Effects of Bromfenac Sodium, Non-Steroidal Anti-Inflammatory Drug, on Acute Ocular Inflammation. Nihon Ganka Gakkai Zasshi, 99, 406-411.

[45] Waterbury, L.D., Silliman, D. and Jolas, T. (2006) Comparison of Cyclooxygenase Inhibitory Activity and Ocular Anti-Inflammatory Effects of Ketorolac Tromethamine and Bromfenac Sodium. Current Medical Research and Opinion, 22, 1133-1140. https://doi.org/10.1185/030079906X112471 